\title{
Agricultural Tractor Cabin Safety Analysis and Test Correlation
}

\author{
Selen Sağsöz Karakulak ${ }^{1}$, Emre Yetkin ${ }^{1}$ \\ 0000-0002-5505-663X, 0000-0003-2360-9735 \\ ${ }^{I}$ TurkTraktor Agricultural Machinery Inc., Istanbul, Turkey
}

\begin{abstract}
Tractors are important vehicles for agricultural fields and they are widely used. Even if they do not be in the traffic due to their intended use, safety of the driver is important if the tractor is rollover. In tractor, the impact energy is provided by cabin or protective profile structure during rollover. Safety test conditions have been established by Organization for Economic Co-operation and Development (OECD) by determining the loads that may occur in case of rollover. According to the standard which developed by OECD, the effects of the energy to be generated during rollover or impact on the structure are examined by performing tests under the specified loads. In this study, static loading test of tractor cabins is simulated by finite element method according to the ISO 3471 standart. Tractor cabin finite element models have been prepared with HyperMesh and HyperCrash software. Nonlinear explicit analysis of the model was performed under the loads applied during the test. . The analysis were carried out using RADIOSS software, based on the operating principle of the load carrying mechanism in order to simulate the test loads. The finite element model is limited to the frame connection points and the deformations are examined for three loading conditions. According to the results which are obtained from the test, the finite element analysis of the designed cabin was also validated.
\end{abstract}

Keywords: Agricultural tractors, cabin strength, ROPS, OECD, ISO 3471

\section{* Corresponding author \\ Selen Sağsöz Karakulak \\ selen.sagsoz@turktraktor.com.tr}

Adress: Koc Camlica Business Center / TurkTraktor R\&D, Unalan, Uskudar, Istanbul/Turkey

Tel:+903122332858

Researh Article

Manuscript

Received 01.11.2019

Revised $\quad 01.03 .2020$

Accepted $\quad 05.03 .2020$

Doi: 10.30939/ijastech..641569

\section{Introduction}

Most of the accidents occurring in agricultural areas are seen in agricultural tractors. The rollover accident of the tractors constitutes the majority of them. In such accidents, the tractor cab or protective profile structure protects the driver's living area under impact forces during the accident and prevents damage to the driver. Tractor cab is a closed mechanism with window and special ventilation system, consisting of parts made of thin-walled metal beams and connected to the tractor. A cab can protect the driver from unfavorable weather conditions, exhaust smoke and other external conditions, reducing noise effects. However, the most important task of the tractor cabin is to protect the driver from the risks at the time of the accident.

In the automotive sector, safety has become an important topic in recent years, which has been studied extensively and has been addressed in many research and development projects. Many standards have been set in order to increase driving safety and to examine vehicle safety within certain control parameters. In order to comply with these standards, manufacturers examine their products at the design stage and take the necessary measures. According to statistics from the United States, in the year of 2001, 9 out of 15 accidents are known to be rollover accidents which means that it is more than $50 \%$ [1]. Another study shows that tractor rollover accidents account for $50 \%$ of all tractor-related deaths. Until the mid-1970s, the number of fatal accidents was high, since Rollover Protective Structures (ROPS) were not present in tractors. For this reason, the seat belt and ROPS are made compulsory as standard equipment [2]. In order to question the safety of agricultural tractors, various standards have been developed by the Organization for Economic Co-operation and Development (OECD) [3]. After the adoption of the OECD codes, it has also become internationally recognized as EEC / EC regulations and ISO standards. In this context, tests are carried out under certain loads on the protective structure of the tractor and the effect of the energy to be generated during rollover or impact is examined. When the design change is made on the main frame of the tractor cab, it is necessary to repeat the test each time. This leads to waste of time and cost. The 
effect of design change on the structure can be examined with the help of FEM analysis, they are taken against negative conditions that may occur in the test. Thus, time and cost losses can be minimized. There are many examples of validation and analysis of cabin safety issues. Studies have shown that the analysis of the cabinet can be correlated with the test and give realistic results [2]. When the effect of the variables on the analysis result is examined, it is concluded that the correct definition of the cabin component geometries and materials will directly affect the location of the cabin center of gravity and will also affect the accuracy of the result. Another point is that the loading points should be applied in the test correctly in the FEM model [4]. ROPS and Falling Object Protective Structure (FOPS) structures are the most important parts that protect the tractor driver in case of an accident. These structures are tested according to OECD Code 4 and Code 10 standards [5]. The code 4 standard provides 3 different loading definitions. These are lateral load, vertical load and longitudinal loads [3]. These loading conditions foresee the impacts of the tractor during rollover.

Baragetti et al., performed cabin analysis according to code 4 standard and compared the results with the actual test results for 4 loading conditions and have made some inferences. They found that the mesh should be of good quality at high deformation points and material properties for all existing elements must be accurately defined by experimental data for validate the test data and analysis data [6]. Molari et al., compared OECD Code 4 and ISO 3471 standards. Code 4 defines 4 different loading conditions as one longitudinal, one vertical, one lateral and one vertical, while ISO 3471 defines one lateral, one vertical and one longitudinal load [7]. Lenain et al., define a full tractor finite element model and evaluated the effects of center of gravity, impact point and weight changes on tractor deformation after longitudinal and lateral rollover. The most important variable is the position of the center of gravity because impact energy to be absorbed by the tractor "cab to its mass is. This variable and especially its height, affects two cases that affect kinetic energy in rollover motion. The position of this point influences the stability of the tractor that is the limit of the tractor slope which limits the rollover movement. Secondly, the position of central of gravity point directly affects the rolling speed of the tractor. The position of the impact point is another important variable and it is related by impact time. If the impact time is long, the angular speed will be high. As a result, the kinetic energy of the cabin will be high and the tractor structure will be changed [4]. Shende et al., investigated the direct effects of loading conditions and vehicle geometry on the ROPS structure. They have realized three different loading conditions as rear, lateral and vertical. On the other hand, they compared Von Misses vs maximum principal stress results [2].

\section{Test Methodology}

The test procedure applied to the protective structures must also be well understood in order to better explain the tests for the tractor front zone. Available for testing tractor protective structures standards are applied to simulate the rollover scenario of the tractor. For this purpose, the protective structures are subjected to a series of loading tests, from the rear, side, top and front. During testing, the ROPS must protect the driver and any part of the tractor must not enter the safe living area that will affect the safety of the driver or the driver should go outside of this critical area and crushing between the tractor and the ground [8]. The safe living zone is defined as "clearance zone in OECD Codes and the seat reference point (SRP) means a vertical plane passing through the center of the steering wheel. When the forces applied from the rear, the side and the front, it is assumed that the loading is perpendicular to the point where the tractor hits the ground. In the top crushing test, loading is performed perpendicular to the ground plane, while the top crushing test force applied, it is assumed that the loading perpendicular to the ground plane. In this sense, there are two different loading conditions in the tractor front zone test [9].

This study was carried out in accordance with ISO 3471:2008 standard, 3 different loads were applied out and cabin strength was investigated. These are lateral load, vertical load and longitudinal loads. The definition of safe living zone in the ISO 3471 standard is made as DLV and it is described in ISO 3164: 2013 [10-11].

\subsection{Description}

The DLV simply represents the safe area of the cabin. Figure 1 shows the linear dimensions of the DLV and is positioned relative to the seat index Point (SIP) [11].

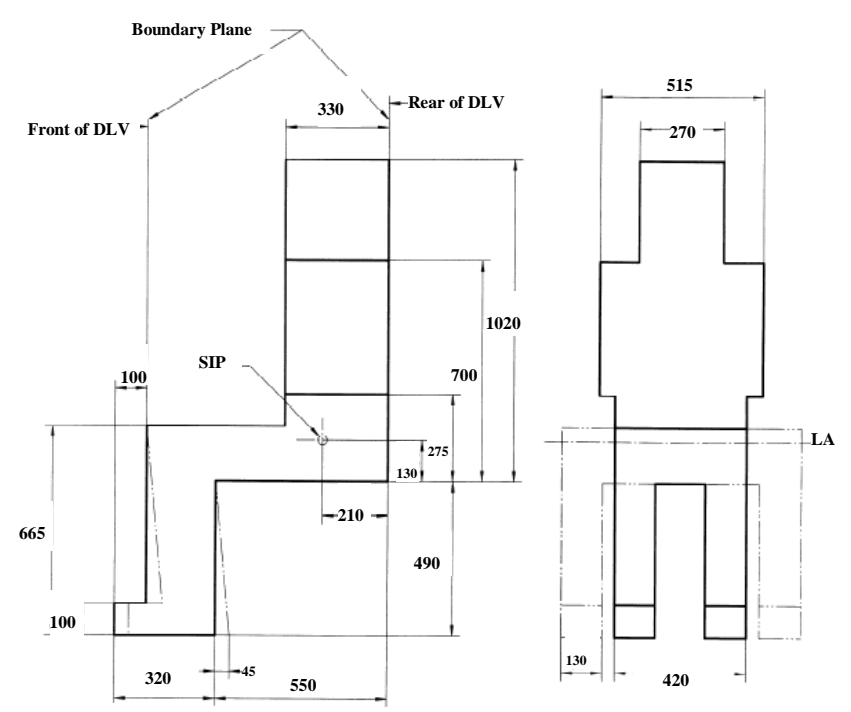

Fig. 1. DLV dimensions 


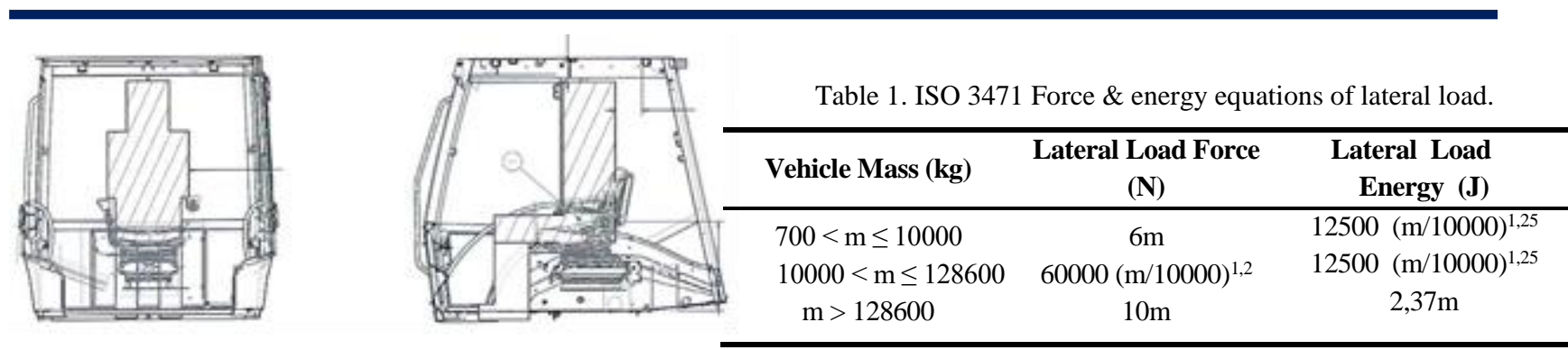

Fig. 2. DLV position in cabin.

For each of the 3 loading conditions, there should be no penetration to the DLV the end of the loading. If any penetration occur during the loading, test should be stopped.

\subsection{Lateral Loading}

During static loading tests, the pistons deform the ROPS by moving rigid plate. All parts affecting the strength of the cab must be assembled and the cab must be mounted in such a way that it is connected to the tractor.

In lateral loading test, the direction of the force should be applied to the top and outermost frame point of the cabin frame so that it is perpendicular to the reference plane. If there is any protrusion on the side that will touch the ground first in case of rollover motion, loading should be applied to that point. The direction and place of the load is shown in Figure 3.

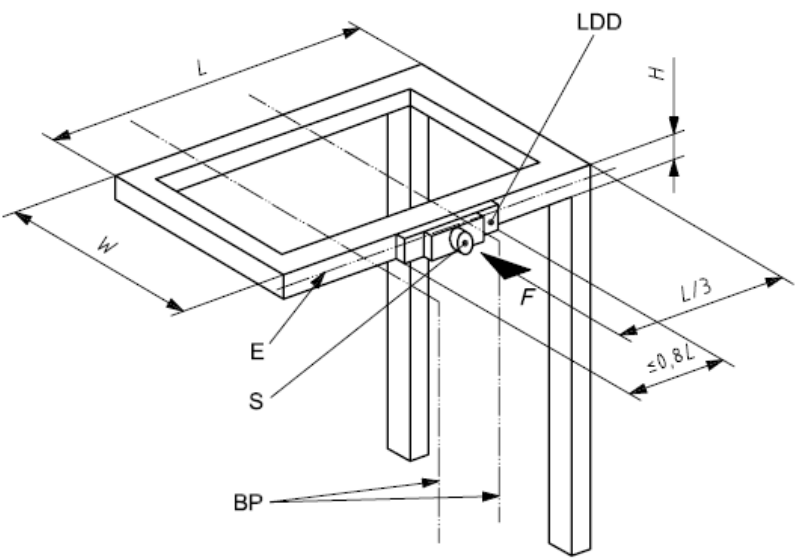

Fig. 3. Lateral load application point.

The lateral force equations to be applied are as shown in table 1 . As shown in the table, there are 2 separate values to be reached for lateral loading. Fist one is, force target and in this study, the weight of the tractor used is $10000 \mathrm{~kg}$, the lateral force is calculated as $60000 \mathrm{~N}$. Second one is, energy target and calculated as $12500 \mathrm{~J}$. Lateral force is applied with the help of a piston at the outermost point and when it reaches $60000 \mathrm{~N}$, check if there is any penetration on the DLV and then the energy is expected to reach $12500 \mathrm{~J}$. If no penetration has been made on the DLV at the end of the loading, this loading condition is successfully completed.
ISO 3471 standard says that ground should be $15^{\circ}$ away from DLV and it describes with Figure 4 [10]. Therefore, the DLV is

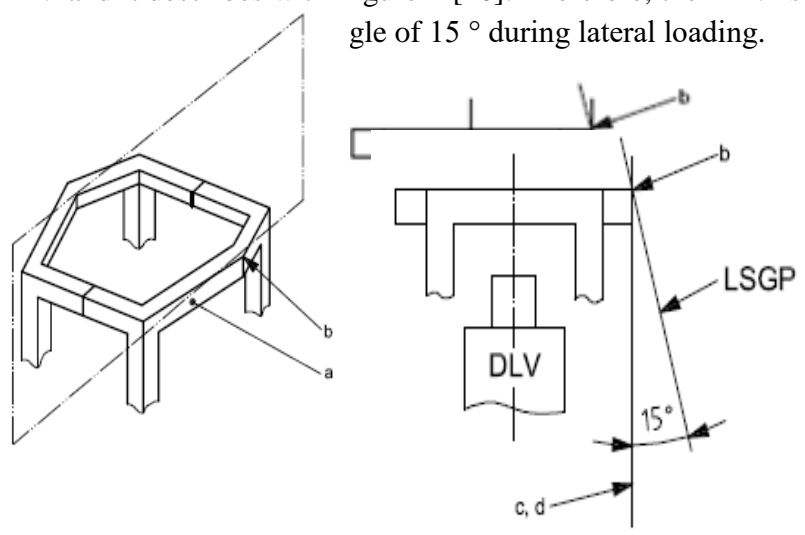

Fig. 4. Determination of lateral simulated ground plane

\subsection{Vertical Loading}

When lateral loading is completed, a vertical load shall be applied to the top of the cabin. The center of the vertical force must be the same as the center of the horizontal force which was applied (Figure 5). When the force value reaches $196100 \mathrm{~N}$ in Table 2, the piston is stopped and left for 5 minutes [11]. DLV is placed perpendicular to the ground. During loading time, there must be no penetration on DLV or no breakage of the ROPS structure.

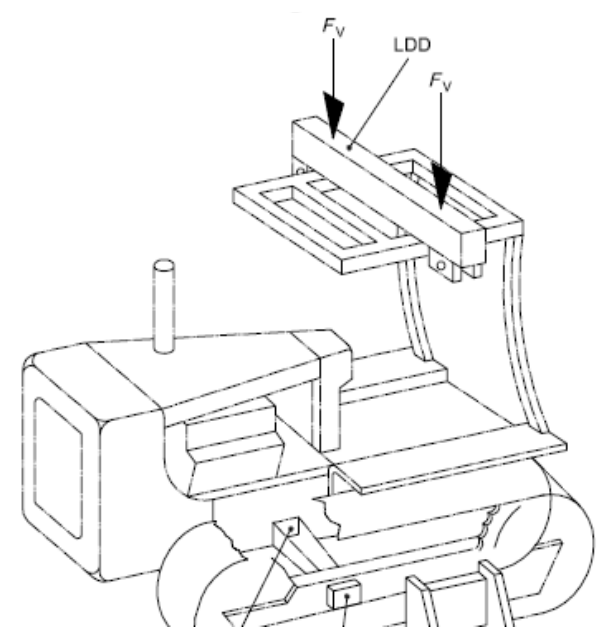

Fig. 5. Vertical load application. 
Table 2. ISO 3471 Force \& energy equations of vertical load.

\begin{tabular}{cc}
\hline Vehicle Mass $(\mathbf{k g})$ & Vertical Load Force $(\mathbf{N})$ \\
\hline $700<\mathrm{m} \leq 10000$ & $19,61 \mathrm{~m}$ \\
$10000<\mathrm{m} \leq 128600$ & \\
$\mathrm{~m}>128600$ & \\
\hline
\end{tabular}

\subsection{Longitudinal Loading}

When vertical loading is completed, a longitudinal load shall be applied to the ROPS. The longitudinal load shall be applied to the upper structural members along the centerline of the cabin as Figure 6. The force application point is determined using the intersecting planes of the rear and top surfaces [11]. Longitudinal loading force is calculated as $48000 \mathrm{~N}$ from Table 3.

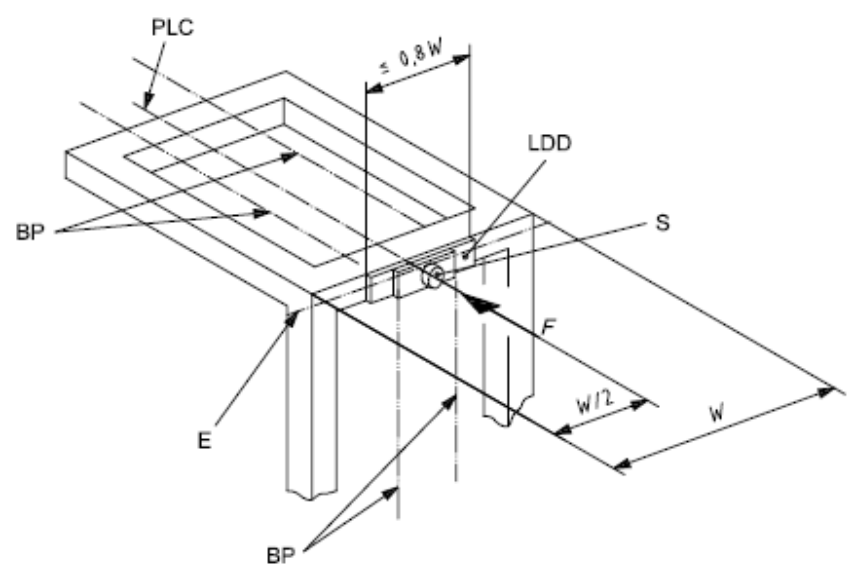

Fig. 6. Longitudinal load application point.

Table 3.ISO 3471 Force \& energy equations of longitudinal load.

\begin{tabular}{cc}
\hline Vehicle Mass (kg) & Longitudinal Load Force $(\mathbf{N})$ \\
\hline $700<\mathrm{m} \leq 10000$ & $4,8 \mathrm{~m}$ \\
$10000<\mathrm{m} \leq 128600$ & $48000(\mathrm{~m} 10000)^{1,2}$ \\
$\mathrm{~m}>128600$ & $8 \mathrm{~m}$ \\
\hline
\end{tabular}

During loading time, there must be no penetration on DLV or no breakage of the cabin structure. When all three loadings have ended, the test is passed successfully if no penetration has occurred on the DLV.

\section{Finite Element Modelling}

For finite element modelling, ALTAIR/HyperWorks CAE software was used. HyperMesh and HyperCrash was used to prepare the FE model and RADIOSS was used as explicit solver. Calculation method was selected as "Explicit Time Integration" to simulate nonlinear material, and failure structure. FE model of cabin is shown in Figure 7.

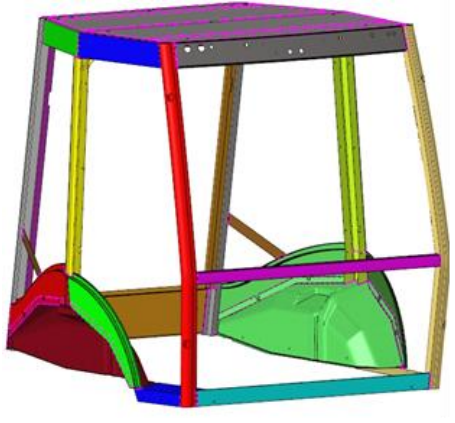

Fig. 7. FEM model of cabin.

Cabin parts were modelled with quad, and tria shell elements. Welds were modelled with 1-D rigid elements. FE model has 347761 elements and 353512 nodes. As it is important that the analysis result is close to the actual test results, the element size was chosen as $5 \mathrm{~mm}$. Literature studies clearly show the importance of mesh density. As the mesh density increases, the test correlation of the analysis increases, but the analysis time is increased [15,16]. Considering the iterations, test correlations and analysis calculation times, our company has set the standard for using 5 $\mathrm{mm}$ mesh size for cabin analysis.

Standard values determined by the company given in Table 4 and Table 5 were used while making the mesh quality control.

Table 4. Mesh Size Targets

\begin{tabular}{|l|l|}
\hline Target length & $5 \mathrm{~mm}$ \\
\hline Min length & $2 \mathrm{~mm}$ \\
\hline Max length & $10 \mathrm{~mm}$ \\
\hline Remove features below & $2 \mathrm{~mm}$ \\
\hline
\end{tabular}

Table 5. Element Quality

\begin{tabular}{|c|c|}
\hline Interior angle (quad) & $>45 \&<135 \mathrm{deg}$ \\
\hline Interior angle (tria) & $>25 \&<130 \mathrm{deg}$ \\
\hline Warpage & $<10$ \\
\hline Aspect ratio & $<5$ \\
\hline Percent of triangle elements & $<10 \%$ \\
\hline Jacobian & $>0.5$ \\
\hline RBE2/RBAR & $\begin{array}{l}\text { No Double De- } \\
\text { pendency, No rigid } \\
\text { loops. }\end{array}$ \\
\hline Duplicate elements & \multicolumn{2}{|c|}{ None } \\
\hline Units & $\begin{array}{l}\text { No free rigid bod- } \\
\text { ies, no rigid body } \\
\text { chains, no free } \\
\text { nodes }\end{array}$ \\
\hline
\end{tabular}


Material model directly affects the results of finite element analysis and it is possible to create more than one material model with different approaches. In this study, Johnson Cook material model equation parameters are defined as material model and Eq. (1) gives material model parameters [12].

$\sigma=\left(A+B \varepsilon_{p}^{n}\right)\left(1+C \ln \frac{\xi}{\varepsilon_{0}}\right)\left(1-T^{m}\right)$

where $\sigma$ denotes the stress, $\varepsilon_{p}$ is the plastic deformation, $A$ is the yield strength, $B$ is the hardening parameter, $n$ is the hardening exponent, and $T^{m}$ is the temperature effect. In the finite element model, the material model is defined as "M2_PLAS_JOHNS_ZERIL" [13]. As inputs for model are given in Table 6.

Table 6. Material Properties.

\begin{tabular}{ccccc}
\hline $\begin{array}{c}\text { Young } \\
\text { Modulus } \\
(\mathbf{G P a})\end{array}$ & $\begin{array}{c}\text { Density } \\
\left(\mathbf{g} / \mathbf{c m}^{\mathbf{3}}\right)\end{array}$ & $\begin{array}{c}\text { Poisson } \\
\text { Ratio }\end{array}$ & $\begin{array}{c}\text { Yield } \\
\text { Strength } \\
(\mathbf{M P a})\end{array}$ & $\begin{array}{c}\text { Tensile } \\
\text { Strength } \\
(\mathbf{M P a})\end{array}$ \\
\hline 210 & 7.8 & 0.3 & 235 & 360 \\
210 & 7.8 & 0.3 & 350 & 510 \\
\hline
\end{tabular}

Johson Cook parameters calculated with the inputs in Table 6 are as, $A=235, B=389, n=0,40$ (Yield Strength $235 \mathrm{MPa}$ ) and $\mathrm{A}=350, \mathrm{~B}=483, \mathrm{n}=0,36$ (Yield Strength 350 $\mathrm{MPa})$.

The friction is another important parameter to affect the analysis result. Friction coefficient is defined as 0.25 and TYPE 7 (general contact) is defined [14]. Thus, the behavior of many variables such as self-contact gaps could be observed. It is also defined the plate in finite element model that will help to apply loading.

In order to place the DLV in the cabin, firstly the SIP point has been determined. Then DLV is created with reference to SIP (Figure 8).

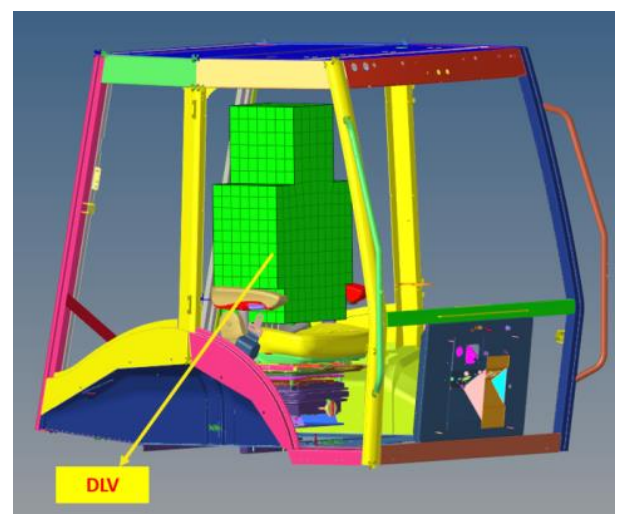

Fig. 8. FEM model of cabin.

\section{Analysis and Test Results}

FEM model of $10000 \mathrm{~kg}$ tractor cabin was built and applied three load cases. Then, tractor cabin analysis was validated with real test.

\subsection{Finite Element Analysis Results}

Firstly, lateral load force was applied on ROPS and the applied force was expected to reach to $60000 \mathrm{~N}$. Applied force shows in Figure 9. Then analysis is continued until the energy reaches $12500 \mathrm{~J}$. In finite element analysis reached $600066 \mathrm{~N}$ when displacement was $250 \mathrm{~mm}$. Analysis was continued and the total displacement reached $281 \mathrm{~mm}$ when kinetic energy was $125001 \mathrm{~J}$. According to the results of the analysis, penetration was not occurred on the DLV during lateral loading. Deformed ROPS structure is shown in Figure 10.

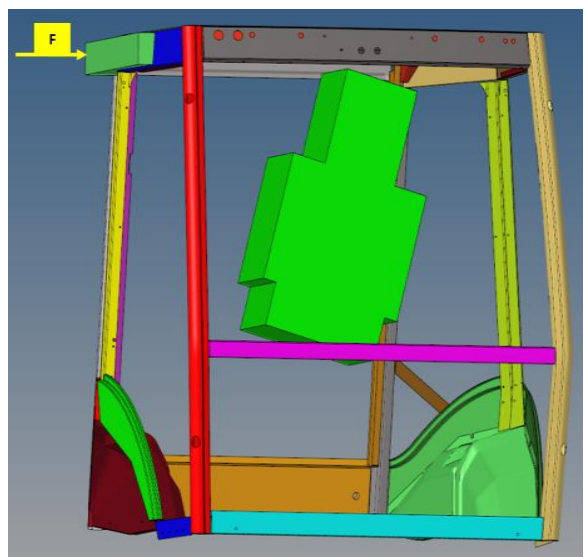

Fig. 9. Lateral loading (FEM).

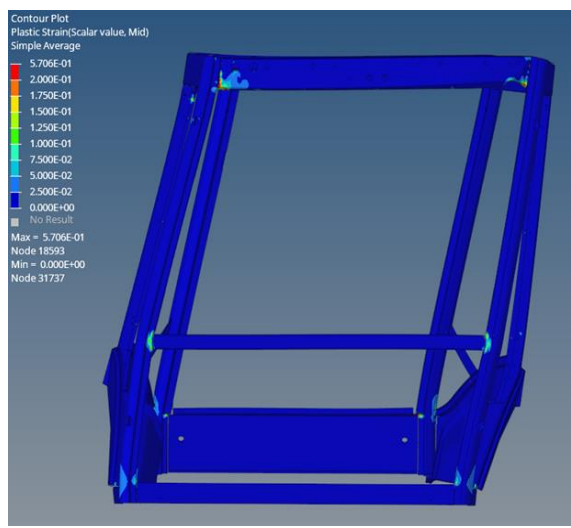

Fig. 10. Plastic strain results after lateral loading.

Secondly, vertical load was applied on ROPS which is shown in Figure 11. When force was reached $196500 \mathrm{~N}$ when node displacement was $34.4 \mathrm{~mm}$, distance was calculated between DLV and roof. This loading condition was also successful because there was no penetration was observed. Deformed structure is shown in Figure 12. 


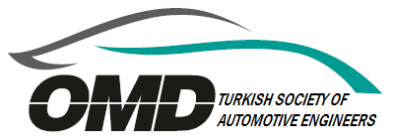

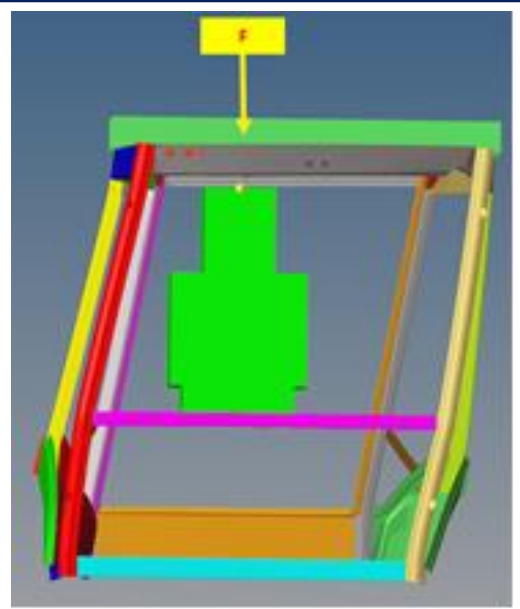

Fig. 11. Vertical loading (FEM).

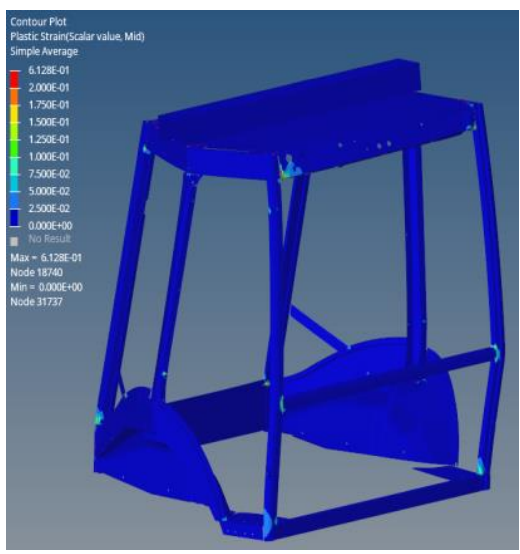

Fig. 12. Plastic strain results after vertical loading.

Lastly, longitudinal loading was applied on deformed shape of ROPS. When force was reached $48971 \mathrm{~N}$, when node displacement was $24.1 \mathrm{~mm}$ distance was calculated between DLV and roof. This loading condition was also successful because there was no penetration was observed. Figure 13 shows the loading direction and Figure 14 shows the deformed shape of ROPS.

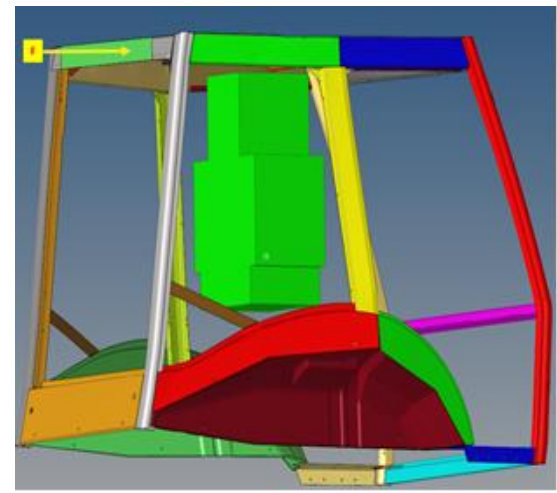

Fig. 13. Longitudinal loading (FEM).

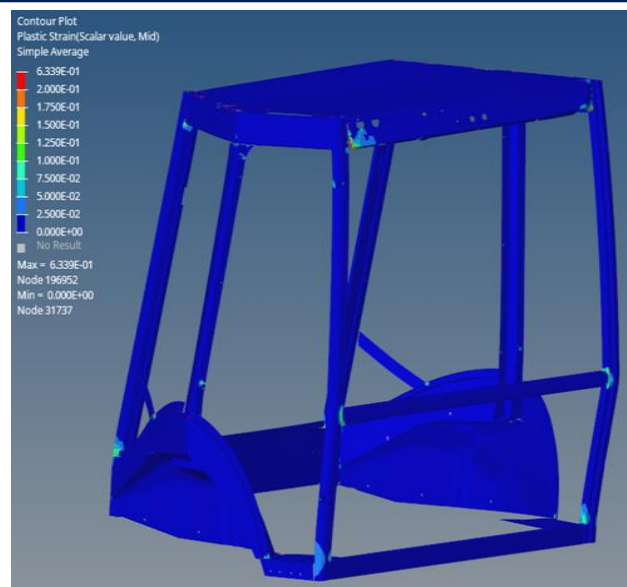

Fig. 14. Plastic strain results after longitudinal loading.

For each loading Explicit Time Integration Model used and after force applied deformed model exported from post-processor to "state" file. State file contains strain and stress data of deformed shape. Thus, the stresses and deformations in the previous loading could be transferred to the next loading condition. This method allows us to obtain values close to the test result with the analysis result.

\subsection{Test Results}

A ROPS structure was prepared for the test as specified in the standard and it was fixed to the ground. Then three loading conditions were carried out consecutively.

Lateral load force applied to reach force target and continued to reach energy target, then stop the deformation and waited 5 minutes when piston on the ROPS. Figure 15 shows the before and after lateral loading. There was no penetration on DLV.
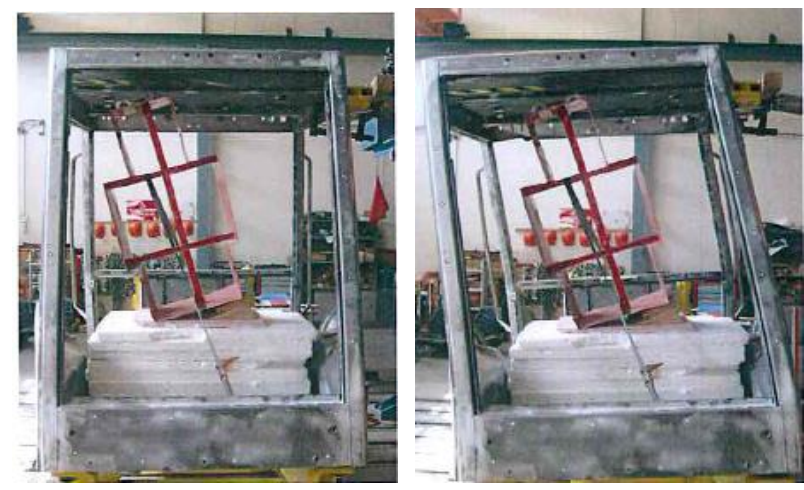

Fig. 15. Lateral loading (before \& after test).

Deformed ROPS structure was repositioned and vertical load applied. When force reached $196360 \mathrm{~N}$, stopped the deformation and checked the DLV penetration. It was not seen any crack on ROPS structure. Figure 16 shows before and after vertical loading. 


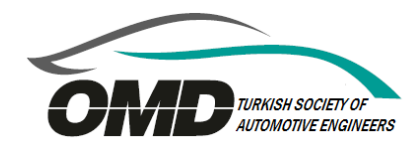

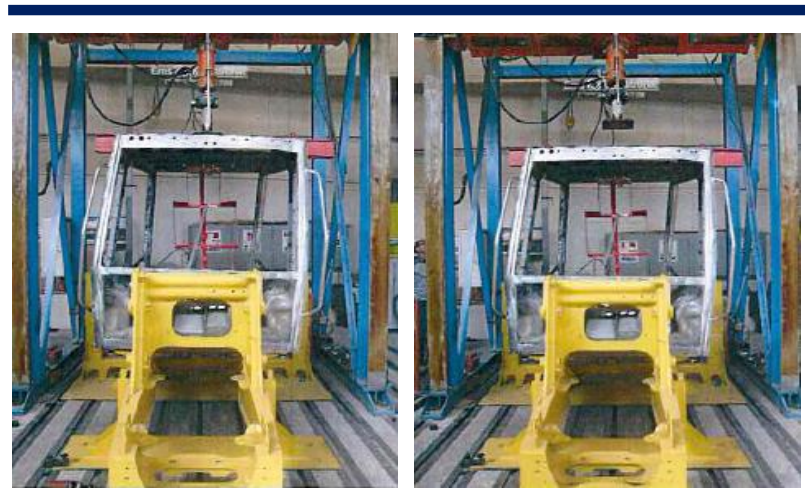

Fig. 16. Vertical loading (before \& after test).

Lastly, longitudinal force was applied to the deformed ROPS structure until force reached 48030 N. Penetration was not observed when force was removed and It was not seen any crack on ROPS structure. Figure 17 shows the before and after longitudinal.
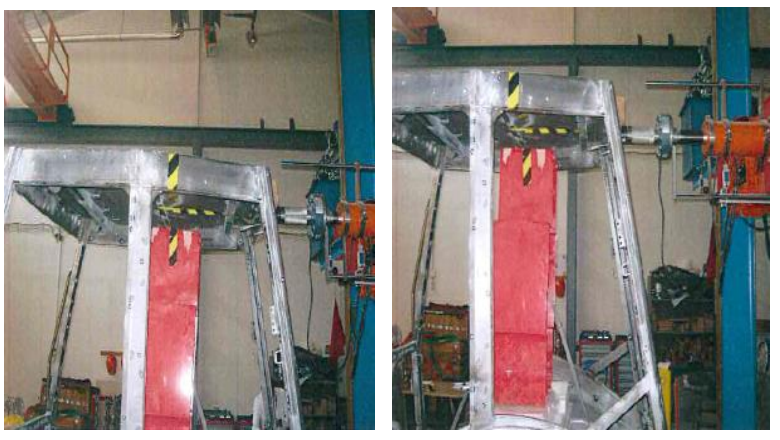

Fig. 17. Longitudinal loading (before \& after test).

Test was successful when all the loads were complete, there was no break on the ROPS structure and no penetration occurred between DLV.

\subsection{Comparing the analysis and test results}

As a result of the study, ROPS analysis was validated by real test. Analysis and test results were compared for each loading conditions and it was found that force and displacement values were close to each other. Forcedisplacement graphs of test and analysis results are given in Figure 18-20.

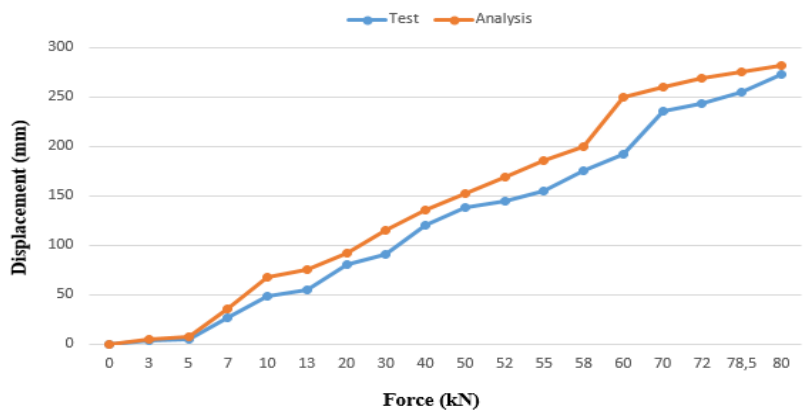

Fig. 18. Lateral loading force \& displacement.

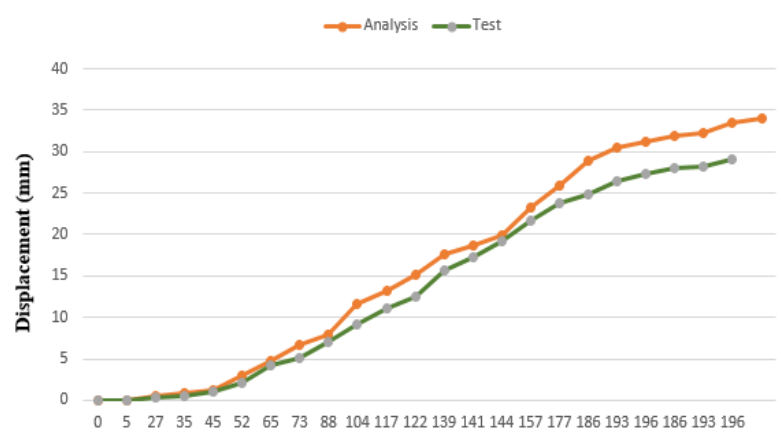

Force $(\mathbf{k N})$

Fig. 19. Vertical loading force \& displacement.

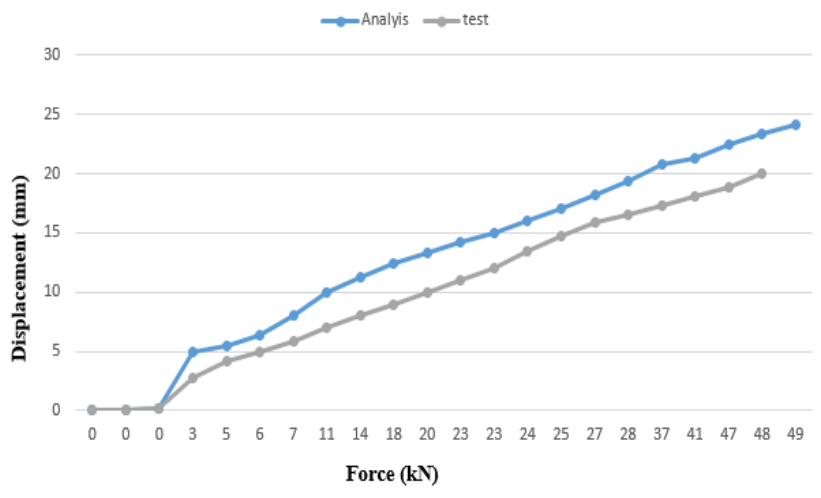

Fig. 20. Longitudinal loading force $\&$ displacement.

Analysis displacement results are higher than test displacement results when reach the target level. For lateral load, maximum displacement was $281 \mathrm{~mm}$ in finite element analysis and this value obtained as 272 in physical test. For vertical load, maximum displacement was 34.4 $\mathrm{mm}$ in finite element analysis and this value obtained as $29.5 \mathrm{~mm}$ in physical test. Lastly, for longitudinal load, maximum displacement was $24.1 \mathrm{~mm}$ in finite element analysis and this value obtained as $20 \mathrm{~mm}$ in physical test. By comparison, the differences between the results are assumed to be normal, because parameters such as contact, mesh density and material model definition make the differences. For most critical loading called lateral load, 97\% correlation with test was achieved. According to literature it is good correlation. For vertical and longitudinal load there are also acceptable correlation that $83 \%$ $86 \%$ was achieved. It can be said that the analysis result is reliable according to these values [17].

When calculating the error between physical test and analysis, the difference between the distance of roof interior and the DLV area before and after the test and the difference values calculated at the end of the analysis were taken into account. 


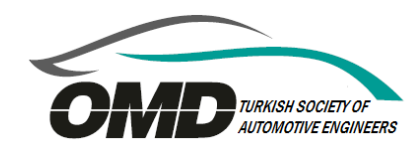

\section{Conclusions}

The biggest risk for vehicles which are used in agricultural areas is the rollover of the tractor. Most of these accidents result in fatal injuries. The regulations issued by the OECD have made it compulsory that all tractors have a protective structure. Therefore the importance of ROPS increased in recent years. Physical ROPS test should be repeated when some structural changes applied. If the test does not meet the required conditions in the physical test, the waste of time and cost is too high because the test will need to be repeated. To avoid these situations, finite element analysis helps us. The results of the analysis can give realistic information about the physical test results.

In this study, a tractor cabin produced by TurkTraktor was tested in OECD standards. Before physical testing, the finite element model of the cabin was prepared and analysis were done. Thus, precautions were taken for the areas that might cause problems in the test and time was saved.

ROPS structure finite element models were built for three different loading conditions and validated with physical test results. Finite element analysis were calculated with RADIOSS. Material properties for non-linear material are defined by Johnson Cook material parameters. Tensile test was performed for all materials used in the building to calculate these parameters and yieldtensile strengths were obtained in this way.

The results of the study showed that the analysis results have similarity around minimum $83 \%$ with test results. While making these calculations, displacement values measured at the end of the test and analysis were used. $17 \%$ difference between the actual test and analysis are predicted to result from welding defects and material properties on the cabin. Due to the nonlinear behavior of the cabin after successive forces, the error rate was higher in the last loading. In this study, the welds of the components are modeled with rigid elements, but the real situation is different. The behavior of the welded region under load differs from that in the analysis. While the structure in the analysis is more rigid, the structure may become more deformed in the physical test. Weld modeling can be studied in subsequent studies to reduce the error rate.

The validation of analysis provides a good example for further studies. We can rely on the results of our analysis and provide time and cost savings by finite element analysis of the structure before testing.

\section{Acknowledgment}

This study has been carried out in TürkTraktör R\&D Center.

\section{Nomenclature}

BP

$$
\text { : Boundary planes of DLV }
$$

$\begin{array}{ll}\text { E } & \begin{array}{l}\text { :horizontal midpoint of upper ROPS structural } \\ \text { member }\end{array} \\ \text { F } & : \text { load force } \\ \text { H } & \text { : height of upper ROPS structural member } \\ \text { L } & \text { : length of ROPS } \\ \text { LAP } & \text { : load application point } \\ \text { LDD } & \text { : load distribution device } \\ \text { S } & \text { : socket } \\ \text { W } & \text { : width of ROPS } \\ \text { m } & \text { : vehicle mass } \\ \text { PLC } & \text { : parallel to longitudinal centerline of machine }\end{array}$

\section{References}

[1] Murphy, D. J., (2002). Summary of fatal farm incidents, 34 Incidents, Pennsylvania State University, Department of Agricultural and Biological Engineering.

[2] Shende R., Kshirsagar V.P. Shelke.(2016). Design and optimization of tractor roll over protective structure, International Journal of Engineering Development and Research, 4(3), 933-939.

[3] Oecd Code 4, (2005). Standard code for the official testing of protective structures on agricultural and forestry tractors. Organization for Economic Co-operation and Development.

[4] Lenain R., Hugo E., Langle T., (2010). Sensitivity of the absorbed energy into a rops during a rollover situation: comparison to the security level proposed into OECD code 4. International Conference on Agricultural Engineering.

[5] Blanco D., Martin C., Ortalde A., (2016). Virtual rops and fops testing on agricultural tractors according to oecd standard code 4 and 10. $14^{\text {th }}$ International LS-DYNA Users Conference.

[6] Bargetti S., Robolotti F., Rota F., (2015). Development of a model for the simulation of rops tests on agricultural tractors cabin: numerical models and experimental verification. International Journal of Engineering Research and Applications, 5(9), 76-86.

[7] Molari G., Badodi M., Guarnieri A., (2010). Fem analysis of rops for agricultural self-moving machines. International Conference Ragusa.

[8] Myers, M. L., (2000). Prevention effectiveness of rollover protective structures, Journal of Agricultural Safety and Health, 6(1): 29-40.

[9] Silleli H., Taşbaş H., Çay İ.C., (2009). A research on the evaluation of front hard point part of agricultural and forestry tractors, Journal of Agricultural Sciences, 15(2), 166-172

[10] ISO 3471, (2008). Earth-moving machinery - Rollover protective structures - Labrotary tests and performance requirements. International Standard.

[11] ISO 3164, (1995). Earth-moving machinery - Laboratory evaluations of protective structures- Specifications for deflection limiting volume. International Standard.

[12] Wang, S., Huang, Y., Xiao, Z., Liu, Y., Liu, H., (2017). A modified johnson-cook model for hot deformation behavior of 


\section{CrMo steel. Metals, 7(9), 337.}

[13] Fokin, D., (2016). Altair Radioss explicit solver. Altair Engineering.

[14] Molaei, SH., Shahbaz, B., Ebrahimi, R., (2014). The relationship between constant friction factor and coefficient of friction in metal forming using finite element analysis, Iranian Journal of Materials Forming, Vol. 1, No. 2, pp 14-22.

[15] Dubey, R.K., (2018). Report on studying the effect of mesh density on finite element analysis and establish an optimal mesh density for finite element analysis of a bridge deck under the effect of self-weight and vehicular dynamic load, International Journal of Advance Research, Ideas and Innovations in Technology, ISSN: 2454-132X, 4(1).

[16] More, S.T., Bindu, R.S., (2015). Effect of mesh size on finite element analysis of plate structure, International Journal of Engineering Science and Innovative Technology, ISSN: 2319-5967, 4(3).

[17]Bathe, K.J., (2014). Finite element procedures, 2nd Editio, p.9. 